\title{
Inter-Regional Cooperation in the Social Sciences: The Latin American Experience*
}

\section{Enrique Oteiza}

The development and organisation of social science in Latin America

Since the late 1940s, when the UN Economic Commission for Latin America was founded, the growth of the social sciences in Latin America has been rapid, with the number of research institutes in the region approximately doubling in the 1950s and again in the 1960s. By 1975 there were about 80 member research institutes in the Latin American Social Science Council (CLACSO), most of them active, though only a few were large in terms of the number of researchers.

There was also a significant expansion in undergraduate level training programmes during the 1950s and 1960s. In many instances this formed part of a wider process of university reform involving an increase in scientific research and training activities in both the natural and the social sciences.

Only a minority of those who obtained a first degree in the social sciences were able to pursue graduate studies, mainly in universities in Europe and the USA. It was this group, for the most part with graduate training outside the region, who staffed the newly created research institutions and became professors in Latin American universities.

Since the 1960s, however, there has been some expansion of post-graduate programmes in the region. New international academic institutions like FLACSO and CELADE provided Masters level courses in sociology, demography and political science. National graduate programmes - in some cases with regional coverage - also emerged at a number of universities and academic institutions such as Escolatina or CIDU in Santiago; CENDES in Venezuela; El Colegio de Mexico and UNAM in Mexico; the Catholic University in Lima; CEUR and the Bariloche Foundation in Argentina; the University of Brasilia and Faculty Candido Mendes in Brazil.

The demand from academic institutions for research and teaching staff grew relatively fast. By 1970, the community of well-trained social scientists in Latin America had reached a considerable size. Simultaneously the demand from governmental agencies and international organisations in the region also grew, with economists as the preferred profession. Of course, the expansion of research and training activities in the social sciences differed significantly among the various Latin American countries. On the whole the large and medium-sized countries in the region developed larger scale facilities than the smaller ones, though political factors were also important.

The rapid progress made during the previous two decades was, however, adversely affected in the 1960 s by the political situation. The rise and multiplication of a new brand of authoritarian regime resulted in the destruction of academic institutions where the social sciences had previously flourished. Not only institutions were damaged or destroyed; an increasing number of social scientists suffered persecution, making it difficult for them to continue their work.

Broadly speaking, then, there was a cycle of rapid growth from 1948 to 1966, followed by a decline. Of course these periods have not been simultaneous in all Latin American countries: authoritarian regimes came into being gradually, until they finally controlled a high proportion of the countries in the region.

In spite of these setbacks, the present level of activity in the social sciences is much higher than in 1950. There is a significant amount of research work going on and the effort to replace the training of graduate Latin American students outside the region by relevant and good quality training inside the area continues. CLACSO's Latin American Graduate Training Programme in the social sciences has, in the last couple of years, brought together some of the best institutes or centres in the region with well integrated research and training programmes.

As a result of this process, significant contributions have been made towards a better understanding of Latin American history and the processes that explain underdevelopment. At the

\footnotetext{
* Published with the permission of UNESCO. This paper was originally prepared for a UNESCO meeting on Interregional Cooperation in the Social Sciences, held in Paris regional Cooperation in the Social Sciences' under the regional Cooperation in the Social Sciences' under the
Reports and Papers in the Social Sciences No. 36 by UNESCO in 1977. This is a revised version of that paper.
} 
same time, important perspectives have been introduced on development problems in general.

But some weaknesses in the way the Latin American social sciences have developed over the last 30 years should also be pointed out. These are mainly a sub-aspect of the more general situation of dependency that exists in the region.

First, there is insufficient local support to sustain the type of research and teaching needed for the long-term development of Latin American societies. This is aggravated by the persecution of social scientists as a result of the generally repressive attitude of dominant groups towards critical or independent intellectuals. This lack of internal support is complemented by an excessive dependence on foreign finance, which tends to distort priorities and impose perspectives which are not always relevant locally.

Second, despite the expansion of graduate training programmes, the expansion of the present stock of Latin American social scientists still depends too much on advanced training in Europe and the USA. The effect of this in terms of alienation, brain drain and irrelevance is wellknown.

Finally, there is an inadequate academic infrastructure in terms of documentation, information systems, archives and data banks. Even at the more traditional level of libraries, the most important Latin American collections are outside the region.

Intra-regional Latin American collaboration in the social sciences

Although progress in the social sciences was already considerable, by 1960 it became clear that more formal and permanent mechanisms of collaboration at regional level were needed. The number of regional, and particularly national, research and training institutions was multiplying fast, but there was little systematic contact and discussion among researchers; lack of information about ongoing research; poor circulation of work produced by the different institutes; and an almost complete absence of collaborative research projects. Collaboration on teaching programmes was non-existent.

On the other hand, very strong institutional links persisted between Latin American research institutions and parent academic institutions in the USA and Western Europe, and these connections flourished, underscoring the complete lack of adequate mechanisms for intra-regional cooperation.

From about 1960 to 1965 , preparatory work was undertaken to establish an institution that could organise a permanent collaborative network in Latin America. A number of different institutional arrangements were discussed, including a federation of the national professional associations of the social science disciplines; an association of university research and teaching units in the social sciences (schools, departments, faculties, institutes); an association of research units, independently of university affiliations.

Finally a decision was made in favour of the last, because of its fairly wide base in terms both of disciplinary and geographical coverage. This choice also permitted the exclusion of traditional groups that were not research oriented (either purely teaching or juridically and philosophically oriented institutions of the old-fashioned type).

The creation of the Latin American Social Science Council was the result. It was formally established by the representatives of 32 research institutions from the area, which in turn became the first Member Centres of the Council. It is governed by a General Assembly, made up of representatives of the Member Centres (now increased to 80 ), and required to meet at least every two years. Apart from discussing and approving the Council's programme and budget, it elects an Executive Committee of 18 members for a period of four years, in which a balance is aimed at between the countries of the region and the various social science disciplines. An Executive Secretary is also appointed by the General Assembly for a period of four years to implement the decisions made by the Assembly and Executive Committee and to monitor permanent activities.

CLACSO's objectives include:

-to improve and stimulate scientific communication within the region and cooperation among the Council's member centres;

-to promote basic and applied research in the different fields of the social sciences, and research and training projects of particular importance to Latin America;

- to stimulate the continuous improvement of teaching and training in the social sciences in Latin America;

- to assist in the mobility of social scientists within the region, and to contribute to a better use of the human academic resources available in Latin America;

--to promote the study of Latin American integration;

- to develop academic cooperation with other areas of the world, particularly Asia and Africa. 
The Council's key instruments for developing collaboration in research on a regional basis are its Working Commissions. These are decentralised collaborative research networks bringing together active researchers in particular fields of knowledge. Each Commission has a coordinator who must be a well-established social scientist in the relevant field of study. At present the following Working Commissions are in existence:

\author{
Economic History \\ Urban and Regional Development \\ Studies on Dependency \\ Rural Studies \\ Science, Technology and Development \\ Population and Development \\ Studies on the State \\ Education and Development \\ Labour Movements.
}

There are also less formal Working Groups which tackle problems on which collaboration between Latin American social scientists and CLACSO centres is just begining. A Working Group on Income Distribution is functioning, and others are under consideration.

CLACSO has also developed a Latin American Graduate Training Programme in the Social Sciences in order to raise the standard of graduate teaching. This has concentrated on improving and regionalising existing national programmes, making better use of the few existing regional centres and developing others in fields or subregions which are not properly covered. The Programme receives support from UNESCO, UNDP and other agencies, particularly in the creation of scholarships to allow good Latin American students to follow the best courses in the region. These agencies also provide support for the mobilisation of teaching staff through visiting professorship schemes, permanent exchanges and discussions about the content and organisation of training programmes.

In contrast to the previous experience of supranational organisation, when social science activities took place under the patronage of institutions and governments located outside Latin America, the establishment of the Council has permitted its Member Centres collectively to define social science policy at a regional level. CLACSO's Working Commissions and Groups define or participate in the definition of research priorities from within Latin America, and decide how to fund or negotiate funds for projects. Similar progress has occurred for graduate training, though as yet to a lesser extent.
The consequence, therefore, of organisation at the intra-regional level has also been a redefinition of inter-regional patterns of cooperation (Amin et al, 1975). The Latin American social sciences are still far from having eliminated the imbalance in their academic relations with the USA and Western Europe, but conditions have improved, allowing a relatively more symmetric collaboration. Exchanges and collaboration with Asia and Africa are still very weak, though thanks to the effort made by the respective regional associations there has been some progress with the support of agencies like UNESCO, The OECD Development Centre and IDRC.

Though CLACSO has been the collaborative Latin American institution 'par excellence' because of its objectives and structure, many other national and regional institutions have played an important role. Among the regional UN agencies, ECLA and CELADE have played an important role. FLACSO, a purely Latin American intergovernmental academic institution, has contributed much to the development of the social sciences in the region, mostly through its regional graduate training programme, in the past devoted mainly to sociology and political science, but now being expanded in terms of both discipline and regional coverage.

Some problems of social science research in Latin America

The emergence of the Latin American social sciences on the international intellectual scene is marked by a number of distinct characteristics, some of which have deep historical roots.

As a society and as a culture, Latin America is marked by a long period of colonial domination from Spain and Portugal over pre-colombian societies. Abundant immigration from Europe provided a dominant upper class, and from Africa, through the institution of slavery, a population to be exploited in addition to the so-called 'Indians'. This combination of populations of very different origins during several centuries of colonial rule had a distinctive impact on social structure and culture. It resulted in a peculiar type of socio-economic formation with a powerful land-owning class and enclaves of plantation and mineral exploitation linked with markets abroad, which still account for certain persistent characteristics of Latin American societies.

During the long-colonial period and from independence (achieved in the nineteenth century) until the present, the continent has been increasingly incorporated in a subordinate role into the expanding capitalist system, the most recent phase 
of which has been based on import substitution and dependent industrialisation.

The nature of Latin American social sciences can be better understood if this is kept in mind. It is the structural characteristics of Latin American societies as they have been shaped over the past centuries that determine the constraints and possibilities of the Latin American social sciences. The evolution of social science is conditioned to some extent by socio-economic structures that perpetuate power in the hands of social groups which need very little in terms of local scientific creativity in order to maintain or enlarge their interests. Their insertion in a broader transnational system makes them dependent on foreign, not domestic knowledge. This helps to explain the very low level of material support provided for scientific activities in general, which is reflected in weak research structures.

There is nevertheless a difference between the more industrialised countries in Latin America and the rest. The former, even if also economically dependent, require more in terms of local social science than the latter. It is the special nature of the knowledge required in the more industrialised countries that has produced a demand for the more 'technocratic' type of social scientist, mostly economists of neoclassical orientation, though there is some room for the more technocratic kind of sociologist. This category of social scientist is known in some Latin American countries as the 'technobureaucrat', and is supposedly apolitical.

But most governments perceive a more critical and socially committed social science as a positive danger, inasmuch as it reveals the mechanisms of domination and exploitation and the forms of insertion in the international system that are at the very root of poverty and underdevelopment. By sad experience it is well known how this form of repression affects the work of social scientists and decreases the possibilities of collaboration. Further, political repression creates obstacles to freedom of circulation of persons and publications. At present it is difficult for nationals of some Latin American countries to get even tourist visas to other countries in the same region, where visits by nationals to other countries which are disapproved of are sometimes penalised. These obstacles to free movement create a structural barrier to communication, which works against collaboration. These problems in terms of scientific institutions and socioeconomic conditioning have been aggravated in the last ten years by an almost chronic crisis of the universities in many countries in the region, as a result of conflicts which are part of a much broader socio-political crisis.

Yet despite these unfavourable conditions there has been a very significant development of the social sciences in the region in the last three decades, as noted earlier, in terms not only of the quantitative growth of research and training activities, but also in terms of relevance, creativity and quality Here is where the experience of regional collaboration seems particularly relevant. For it is this that has permitted Latin American social scientists and institutions partially to overcome the limitations stemming from the structure of local societies and their foreign dependency.

Active intra-regional collaboration has created a situation in which ideas have circulated fast. Publication and distribution schemes have contributed to this process, aided by the fact that there are only two similar languages (Spanish and Portuguese) as the vehicles for communication.

As repression extended over Latin America, collaboration also became important in terms of solidarity among colleagues. This palliated to some extent the effects of ideological and political persecution: unemployment, gaol and exile.

\section{Possibilities and constraints for future interna- tional collaboration}

The experience of intra-regional collaboration in the social sciences proves that very signficant improvements in academic work can result. There are now regional institutions especially devoted to intra-regional collaboration in Africa, Asia, Europe and Latin America (CLACSO, CODESRIA, EADI and ADIPA). Their success should also be reflected in a redefinition of interregional academic exchanges and collaboration, in the hope of transforming the present unbalanced patterns into better-balanced ones.

The constraints which limit intra-regional collaboration have already been mentioned. They include a lack of an adequate scientific research and educational infrastructure, lack of local funds and corresponding dependence on extraregional funds, advanced training in Europe and the USA, and finally the adverse consequences of political repression on critical social science research and analysis. The difficulties of interregional collaboration are even greater. "Collaboration' between underdeveloped and developed regions is substantial, but it is of the wrong sort. On the other hand, academic collaboration between Asia, Africa and Latin America has been traditionally non-existent. The colonial linkages 
and contemporary forms of insertion of the countries of these regions in the world economic, political and cultural system has shaped powerful centre-periphery networks but has not connected the regions in the periphery to each other.

There are thus formidable obstacles to overcome. Because of the lack of specialised programmes for this purpose, including the lack of scholarships and exchange and training facilities, there are too few social scientists in Africa, Asia and Latin America with knowledge about the history and development problems of regions other than their own. There are also few channels for the inter-regional circulation of books and journals aggravated by insufficient translation and publication. At a more general level, the resources that international organisations and governments channel into exchange and collaboration programmes are amazingly inadequate. Yet much could be gained: the understanding of problems of underdevelopment and how to overcome them could be broadened, while there are obvious advantages in cooperating on the study of the processes going on in the central capitalist countries, the industrialised socialist countries, and the international system in general.

\section{Recommendations}

A number of recommendations may be addressed to international and regional organisations already involved in programmes of exchange and collaboration in the social sciences such as UNESCO and other UN agencies, the International Social Science Council and the international disciplinary associations in the social sciences, the regional associations and the OECD Development Centre. They are also relevant to national institutions which play an international academic role such as IDRC of Canada and the national Social Science Councils in a number of countries.

It is recommended that they should:

- assign resources in order to reinforce interregional collaboration in research between Third World regions;

- establish scholarship programmes in order to train some Third World social science graduate students in underdeveloped regions outside their own;

-re-assign resources so as to allow the exchange of visiting professors and researchers within the Third World regions;

-establish translation and publication programmes in order to ensure that research done in one Third World region is available in the language of others (particularly translation from Spanish and Portuguese into English and French); -establish inter-regional distribution or relevant publications to the main academic libraries;

-support good journals published in Asia, Africa and Latin America;

-support services disseminating information about research and training institutions and ongoing research of the type provided by the OECD Development Centre;

- support inter-regional meetings and seminars organised as much as possible by, or jointly with, the respective regional associations;

-revise the mechanisms for defining research priorities so that relevant regional and local academic institutions participate effectively;

-reinforce programmes for graduate training in the social sciences within the Third World;

- defend the rights of social scientists to carry out their work without being subjected to the various forms of persecution they encounter in many underdeveloped countries;

-oppose restrictions on the circulation of social scientists, which are already damaging academic work in some areas, particularly Latin America; -establish balanced inter-regional cooperation (avoid academic imperialism in its different forms);

-verify that each collaborative project or programme contributes towards the reinforcement of local institutions in the Third World, so that dependency is reduced.

\section{Glossary of International Organisations}

ADIPA Association of Development Research and Training Institutes of Asia and the Pacific (Regional)

CELADE Latin American Centre of Demography (Regional)

CENDES Centre of Development Studies, Central University, Caracas, Venezuela

CEUR Centre of Urban and Regional Studies, Torcuato Di Tella Institute, Buenos Aires, Argentina

CIDU-IPU Institute of Urban Development Planning, Catholic University, Santiago, Chile

CLACSO Latin American Social Science Council (Regional)

CODESRIA Council for the Development of Economic and Social Research in Africa (Regional)

EADI European Association of Development Research and Training Institutes ( $R e-$ gional) 
ECLA UN Economic Commission for Latin America

FLACSO Latin American School of Social Science (Regional)

IDRC International Development Research Center, Canada

OECD Organisation for Economic Cooperation and Development

UNAM Universidad Nacional Autónoma de México

UNDF United Nations Development Fund

UNESCO United Nations Educational, Scientific and Cultural Organisation

\section{References and Bibliography}

Samir Amin, Fossi Giulio, Jolly Richard, Oteiza Enrique, Wignaraja Poona, 1975, 'New Forms of Collaboration in Development Research and Training, International Social Science Journal, Vol. XXVII, No. 4, Paris.

Borda, Orlando Fals, 1970, Ciencia Propia y Colonialismo Intelectual, Editorial Nuestro Tiempo, Mexico.
Casanova, Pablo Gonzalez y Guillermo Bonfil, 1968, Las Ciencias Sociales y la Antropologia, en Ediciones Productividad, Mexico.

CLACSO, 1968 to 1976, Memorias Anuales y Boletines.

Fernandez, Florestán, 1958, O padrao de trabalho Cientifico dos Sociologos Brasileinos, Revista Brasileira de Estuodos Políticos, Minas Gerais.

FLACSO, El Papel de la FLACSO en los Estudios sobre el Desarrollo Económico, 1959, documento de trabajo presentado al Seminario sobre 'Resistencia al Cambio', Rio de Janeiro, Octubre.

Germani, Gino, 1964, La Sociologia en America Latina, EUDEBA, Buenos Aires.

Graciarena, Jorge, 1974, La Ensenanza de las Ciencias Sociales en América Latina, Editorial Paidós, Buenos Aires.

Horowitz, Irving Louis, 1967, The Rise and Fall of Project Camelot, The MIT Press, Cambridge (Mass.).

Ianni, Octavio, 1976, Sociología de Sociología Latino-Americana, Civilizacao Brasileira, 2 Edicao, Rio de Janeiro.

Marsal, Juan Francisco, 1973, La Investigación Sociológica en América Latina, Papers, Vol. I, Universidad Autónoma de Barcelona. 